\title{
Prevalence of HPV infection among Greek women attending a gynecological outpatient clinic
}

\author{
Petroula Stamataki ${ }^{1}$, Athanasia Papazafiropoulou ${ }^{2}$, Ioannis Elefsiniotis ${ }^{3}$, Margarita Giannakopoulou ${ }^{3}$, \\ Hero Brokalaki ${ }^{3}$, Eleni Apostolopoulou ${ }^{3}$, Pavlos Sarafis $^{1}$, George Saroglou ${ }^{3}$
}

\begin{abstract}
Background: Human papillomavirus (HPV) infection is a causative factor for cervical cancer. Early detection of high risk HPV types might help to identify women at high risk of cervical cancer. The aim of the present study was to examine the HPV prevalence and distribution in cervical smears in a sample of Greek women attending a gynecological outpatient clinic and to explore the determinants of the infection.

Methods: A total of 225 women were studied. All women underwent a regular gynecological control. 35 HPV types were studied; $6,11,16,18,26,31,33,35,39,40,42,43,44,45,51,52,53,54,56,58,59,61,62,66,68,70,71$, $72,73,81,82,83,84,85$ and 89. Also, basic demographic information, sociodemographic characteristics and sexual behavior were recorded.

Results: HPV was detected in $22.7 \%$ of the study population. The percentage of the newly diagnosed women with HPV infection was 17.3\%. HPV-16 was the most common type detected (5.3\%) followed by HPV-53 (4.9\%). 66.2\% of the study participants had a Pap test during the last year without any abnormalities. HPV infection was related positively with alcohol consumption (OR: 2.19, 95\% Cl: 1.04-4.63, $\mathrm{P}=0.04$ ) and number of sexual partners (OR: 2.16, 95\% Cl: 1.44-3.25, P < 0.001), and negatively with age (OR: 0.93, 95\% Cl: 0.87-0.99, P = 0.03), and monthly income (OR: 0.63, 95\% Cl: 0.44-0.89, P = 0.01).

Conclusion: The prevalence of HPV in women attending an outpatient clinic is high. Number of sexual partners and alcohol consumption were the most significant risk factors for HPV infection, followed by young age and lower income.
\end{abstract}

\section{Background}

Cervical cancer is the second most common cancer in women worldwide [1]. Several studies have strongly implicated human papillomavirus (HPV) infection as a causative factor in the development of cervical cancer $[2,3]$. Based on their association with cervical cancer, HPV can be grouped to high-risk (such as HPV-16, -18, -31, and -45) and low-risk HPV types (such as 6, 11, 42, 43, and 44) [4]. High-risk HPV types are present in over 99\% of cervical cancers and in the vast majority of cases of high grade cervical intraepithelial neoplasia $[5,6]$.

* Correspondence: pathan@ath.forthnet.gr

${ }^{2} 3$ rdDepartment of Internal Medicine and Center of Diabetes, Genera

Hospital of Nikaia "Ag. Panteleimon", 3 D.Mantouvalou, 18454 Nikaia, Greece
Worldwide, approximately, 70\% of cervical cancers are due to HPV types 16 and 18 [3].

Women with normal cervical cytology who are infected with high risk HPV type have an approximately 100-fold increased risk of developing cervical cancer compared to uninfected women [7]. Therefore, it has been suggested that high risk HPV detection might be used as a tool to identify women at high risk of cervical cancer, in addition to Pap smears [7,8]. Furthermore, the development of HPV vaccines and implementation of vaccination programs might help to reduce the burden of disease [9]. Especially, vaccination against HPV types 16 and 18 potentially prevents more than two thirds of cervical cancer cases worldwide. However, the impact of an HPV vaccination in different geographical 
regions will be related to the prevalence of HPV types 16 and 18 in the different populations [10].

Since, the prevalence of the high risk HPV types varies among different populations we conducted the present study in order to examine the HPV prevalence and distribution in cervical smears in a sample of Greek women attending a gynecological outpatient clinic and to explore the determinants of the infection.

\section{Methods \\ Population}

The study population consisted of a consecutive sample of 225 women attending the gynecological outpatient clinic of the Maternal and Perinatal Hospital "Elena Venizelou" between October 2007 and May 2008, for regular gynecological control. "Elena Venizelou" Hospital is a tertiary maternal hospital responsible for the greater region of Athens, the capital of Greece. Pregnant women or women with a recent delivery were not enrolled into the study. The refusal rate was low; only 2 women denied taking part into the study.

Basic demographic information, sociodemographic characteristics, medical history, smoking status, alcohol consumption and sexual and reproductive behaviour was obtained at the time of the gynecological visit by a study nurse. Additional questions were asked on age at first sex, number of lifetime partners, past history of sexually transmitted infections, and use of a condom.

Participants were considered as newly diagnosed cases for HPV infection if they had a negative history for HPV infection according to their medical records. In addition, newly diagnosed cases included women who had never been screened for HPV infection. Subjects were considered as non-smokers if they have never smoked or if they had given up smoking for at least three consecutive years. Heavy drinking was defined as consuming an average of more than 1 drink per day. Participants were stratified according to their monthly income and education level as it is stated at Additional file 1, Table S1. Females whose monthly incomes did not exceed 1,000 Euros were considered as low income. High education level was defined as attending a college or a university.

All subjects underwent their scheduled examination, which included the placement of a speculum in the vagina, visualization of the cervix, and collection of cervical cells using a wooden Ayre spatula and endocervical brush. After the preparation of a standard cervical smear, the remaining cells were placed in tubes with $0.9 \%$ saline and stored at $-20^{\circ} \mathrm{C}$ prepared for HPV molecular analysis. Pap smears were classified according to the Bethesda system by local cytopathologists.

The Hospital's ethical committee provided approval for this study. All participants gave their written consent before enrollment to the study. The study was in accordance with the Helsinki declaration.

\section{HPV DNA Detection Techniques Nucleic acid isolation}

The cervical cells removed from the swabs and centrifuged in order to be in a pellet form. The supernatant discarded and the remaining cells were dissolved in 100 $\mu \mathrm{l} 1 \times$ Phosphate Buffer Saline (PBS). The dissolved cells transferred to $200 \mu \mathrm{l}$ Tissue Lysis Buffer and $20 \mu \mathrm{l}$ Proteinase $K$ according the instruction manual of CLINICAL ARRAY 'S (HPV) (Biogenomica Spain). The extracted DNA eluted in $100 \mu$ l Elution buffer (Biogenomica Spain) and stored in $-20^{\circ} \mathrm{C}$. The sensitivity and specificity of the CLINICAL ARRAY' S HPV kit is $92.3 \%$ and $89 \%$, respectively [11].

\section{PCR Amplification}

Five microliters $(5 \mu \mathrm{l})$ of eluted DNA were used in the PCR amplification of pre alliquoted ready to use vialskept at $-20^{\circ} \mathrm{C}$ in alliquots (Biogenomica Spain). The PCR reaction includes two internal controls in order to avoid the false negative results from the extraction procedure and from the PCR inhibitors. The first amplifies a 892 bp fragment of the human CFTR gene and indicates the DNA existence and the second is a $1202 \mathrm{bp}$ fragment from a modified plasmid and indicates if there is inhibitors or not.

\section{Hybridization}

The PCR product denaturated in $95^{\circ} \mathrm{C}$ for 15 minutes in iQ Thermocycler and then thawed in $4^{\circ} \mathrm{C}$. Five microliters $(5 \mu \mathrm{l})$ of the PCR product proceeded in hybridization on the specific Array Tubes according the instruction manual (Biogenomica Spain) on the ATS Workstation (CLONDIAG Chip Technologies GMBH). The hybridization results were interpreted by the Specific CLINICAL ARRAYS Human Papilloma virus software program which it has been preinstalled and ready to use on the ATS Workstation (CLONDIAG Chip Technologies GMBH).

The following 35 HPV types were studied; $6,11,16$, $18,26,31,33,35,39,40,42,43,44,45,51,52,53,54$, $56,58,59,61,62,66,68,70,71,72,73,81,82,83,84$, 85 and 89 . The oncogenic risk of the HPV types detectable with CE marked and IVD marked kit of Genomica are according to the Munoz et al [12].

A recent meta-analysis examined the association between detection of HPV DNA and high-grade cervical intraepithelial neoplasia and invasive cervical cancer, showing a strong association [13].

\section{Statistical Analysis}

Statistical analysis was preformed using programs available in the SPSS statistical package (SPSS 15.0, Chicago, USA). All variables were tested for normal distribution 
of the data. Data are shown as mean \pm SD, unless it is stated otherwise. A two sample $t$-test was used to assess differences in continuous variables, while a chi-square test was used for categorical variables. Univariate binary logistic analysis was performed to look for the relationship between HPV infection and the variables of interest in the sample population. Then, multivariate analysis was performed (backward stepwise method) to look for independent associations between HPV infection and the variables of interest. All independent variables in the multivariate analysis were tested for multicolinearity. $\mathrm{P}<0.05$ (two-tailed) was considered statistically significant.

\section{Results}

\section{Characteristics of the study population}

The characteristics of the study population are summarized in Additional file 1, Table S1. The study population consisted of 225 women aged 16 to 45 years (mean age \pm standard deviation: $30.7 \pm 6.8$ years). Most of the participating women had high (68.4\%) educational level, were unmarried (52.4\%), had their first sexual intercourse before the age of $20(67.1 \%)$, reported a single regular sexual partner during the last year (76.4\%). Of the married women $19.5 \%$ had at least two full term pregnancies. $55.1 \%$ of the participants reported more than 3 sexual partners during their lifetime, and $29.3 \%$ had more than 5 sexual intercourses monthly. $45.3 \%$ of the study participants had high monthly income.

Condom was the most common contraceptive method ever used (58.6\%). It is noteworthy that almost the one third of the study participants did not use any contraceptive method (34.2\%). Of the study population, $10.6 \%$ had a history of a previous HPV infection and $48 \%$ a history of sexually transmitted disease. $8.0 \%$ had never done a Pap test, while $66.2 \%$ had a Pap test during the last year without any abnormalities. Only one third of the women were smokers $(39.1 \%)$, and $48.8 \%$ reported regular alcohol consumption.

\section{Characteristics of women positive for HPV infection}

The age of HPV-positive women $(\mathrm{n}=51)$ was (mean age \pm standard deviation) $28.5 \pm 6.7$ years. Condom was the most common contraceptive method ever used (60.8\%), while $29.4 \%$ did not use any contraceptive method. Of the HPV-positive women, 23.5\% had a history of a previous HPV infection and $54.9 \%$ a history of sexually transmitted disease. $13.7 \%$ had never done a Pap test, while $58.8 \%$ had a Pap test during the last year. $55.0 \%$ of the HPV-positive women were smokers and $62.8 \%$ reported regular alcohol consumption (Additional file 1, Table S1).

\section{HPV prevalence and subtypes}

HPV was detected in 51 of the 225 women examined (22.7\%) (6 positive for HPV-6, 12 for HPV-16, 2 for HPV-18, 1 for HPV-31, 2 for HPV-33, 2 for HPV-39, 3 for HPV-51, 8 for HPV-53, 2 for HPV-58, 2 for HPV61, 1 for HPV-62, 3 for HPV-66, 3 for HPV-81, 2 for HPV-83 and 2 for HPV-84). The percentage of the newly diagnosed women with HPV infection was $17.3 \%$ $(39 / 225)$. In addition, it must be mentioned that 12 women with a previous history for HPV infection were found in the HPV negative subsample. These cases were included in the HPV-negative group for the further analysis.

$16.4 \%(37 / 225)$ of the study population was infected with a single type and $6.2 \%(14 / 225)$ was infected with at least two HPV types. In the entire study population, HPV-16 was the most common type detected (5.3\%) either as a single type or in combination with other types, followed by HPV-53 (4.9\%). It is noteworthy that the prevalence of oncogenic HPV-18 was low (0.9\%). Oncogenic (HPV 16, 18, 31, 33, 39, 51, 53, 58) and nononcogenic (HPV 6, 61, 62, 66, 81, 83, 84) types were detected in $14.2 \%$ and $8.2 \%$ of the HPV-positive women, respectively.

The prevalence of HPV infection among females aged 21 to 30 years was $26.6 \%$ whereas the corresponding prevalence among females aged 16 to 20 years was $57.1 \%$. In detail, the prevalence of HPV-16 and HPV-53 among females aged 21 to 30 years old were $5.5 \%, 2.8 \%$, respectively, whereas the corresponding prevalences among females aged 16 to 20 years were $14.3 \%$ and $14.3 \%$, respectively (Figure 1 ).

\section{Risk factors for HPV infection}

The univariate logistic analysis showed significant associations between HPV infection and age [odds ratio (OR): 0.94, 95\% Confidence Intervals (95\% CI): 0.890.98], monthly income (OR: 0.65, 95\% CI: 0.48-0.89), marital status (OR: 0.37, 95\% CI: 0.18-0.73), number of full term pregnancies (OR: 0.58, 95\% CI: 0.36-0.94), number of sexual partners (OR: $2.17,95 \% \mathrm{CI}: 1.50-3.15)$, smoking status (OR: 1.42, 95\% CI: 1.08-1.85), and alcohol consumption (OR: 2.27, 95\% CI: 1.18-4.35). No any significant relationships were found between HPV infection and educational level, nationality, methods of contraception, age at first sexual intercourse, and history of previous HPV infection or other sexual transmitted diseases (Additional file 2, Table S2).

Multivariate analysis demonstrated, after controlling for smoking, marital status, and number of full term pregnancies, that HPV infection was related positively with alcohol consumption (OR: 2.19, 95\% CI: 1.04-4.63) and number of sexual partners (OR: 2.16 , 95\% CI: 


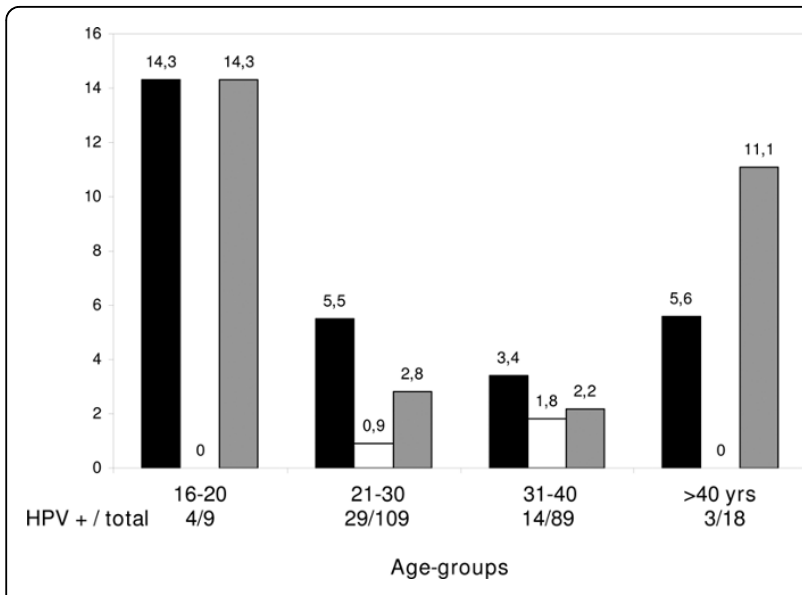

Figure 1 The prevalence of HPV-16, HPV-18 and HPV-53 according to the age groups (the values are shown as \%). "black square", HPV-16; "white square", HPV-18; "grey square", HPV-53.

1.44-3.25), and negatively with age (OR: $0.93,95 \% \mathrm{CI}$ : $0.87-0.99$ ) and monthly income (OR: $0.63,95 \%$ CI: $0.44-$ 0.89) (Additional file 2, Table S2).

\section{Discussion}

Prevalence of HPV DNA in a sample of Greek females aged 16 to 45 years was $22.7 \%$, with the highest prevalence $(57.1 \%)$ among women aged 16 to 20 years.

The percentage of the newly diagnosed women with HPV infection was $17.3 \%$. Oncogenic HPV types were detected in $14.2 \%$ of the HPV-positive women. The overall prevalence of high risk HPV-16, HPV-53 and HPV-18 were $5.3 \%, 4.9 \%$ and $0.9 \%$ respectively. Similar prevalence of HPV-positive women has been reported in a large sample of US females aged 14 to 59 years (26.8\%) [14]. Other studies in Europe have yielded similar findings in healthy women [15] as well as women with history of cervical cancer [16]. A recent study in our country demonstrated that HPV DNA was positive in $23.6 \%$ of cytologically normal women [17]. Similar rates have been confirmed by a previous study in malignant biopsies in Greece [18] and even higher rates in another study in asymptomatic women [19]. However, a study in healthy women by Agorastos et al. reported one of the lowest HPV prevalence ever observed internationally (2.5\%) [20]. Also, low prevalence of HPVpositive women has been reported in studies from Spain [21] and Vietnam [22].

HPV-16 was the most prevalent oncogenic type either as a single type or in combination with other types, while the prevalence of HPV-18 was low. A lot of studies in different populations have shown that HPV-16 was the most common among the others HPV types [22-25]. Even higher prevalence of HPV-16 has been described in different geographic regions ranging from
43.9\% in Asia to $72.4 \%$ in Africa in women with invasive cervical cancer [12]. Furthermore, it is known that HPV16 represents the most commonly identified HPV type in low- and high-grade cervical lesions as well as cervical cancer worldwide [26]. However, a low prevalence of HPV-16, HPV-53 and HPV-18 has been reported in the USA [14]. The prevalence of HPV-18 (0.8\%) was similar to that of the present study [14]. On the contrary, studies from our country using histological samples have reported higher prevalence of HPV-18 [18,27,28]. A study by Kroupis et al., in a sample of Greek women with a history of cervical lesions reported a higher prevalence of HPV-53 [17].

Of the total study population, $16.4 \%$ was infected with a single type and $6.2 \%$ was infected with at least two HPV types. The observed prevalence of multiple infections is low in comparison with the results from studies from different countries [29-35]. The presence of multiple infections was 0\% in Brazil [29], 5.3\% in Morocco [30], 9.8\% in Thailand [31], 14.3\% in Philippines [32], $16.7 \%$ in Paraguay [33], 28\% in The Netherlands [34], and $39 \%$ in Costa Rica [35]. In our country a recent study showed that the prevalence of multiple infections was $21.2 \%$ [17]. These differences in prevalence of multiple infections could be due to differences in the technique used or real differences in the prevalence of the HPV types in the populations studied.

The results of the multivariate analysis demonstrated that HPV infection was related positively with alcohol consumption and number of sexual partners, and negatively with age and monthly income. A lot of previous studies have showed that the main risk factor for HPV infection was the number of sexual partners [36-38]. Also, alcohol consumption was an important risk factor. A simply explanation is that alcohol consumption might lead to unsafe sexual behavior and to less adherences to contraceptive methods. However, the literature data regarding the potential relationship between alcohol consumption and HPV infection are conflicting. A previous study showed that there is a positive relationship between alcohol and HPV infection [39], while a recent one showed no relationship [40]. On the contrary, HPV infection declined with increasing age. Importantly, other studies also reported the increaased HPV infection with aging, suggesting the biological effect, such as HPV immunity acquired over time $[35,38,41]$. The same pattern was observed in a previous study from our country [20]. Finally, low monthly income was a significant determinant of HPV infection. Two studies in the USA have showed that high-risk HPV infection is common in poor women $[42,43]$.

Our study has some limitations. As it is mentioned above, 12 women with a previous HPV infection were found in the HPV-negative subgroup. This is partially 
explained by the results of two studies showing that a single negative HPV test result could lead to missed HPV infection [44] and that HPV test has low specificity [45]. In addition, the number of the participants as well as the age range in our study sample was relatively limited; only women aged 16-45 years were included. Therefore, the results of the present study can not be extrapolated to the total female population of our country. However, since the outpatient clinic is a referral one the results of the present study give us important information regarding the prevalence of HPV infection among young and middle aged women.

\section{Conclusions}

In conclusion, the prevalence of HPV in women attending an outpatient clinic is high showing the importance of the early screening as well as the necessity of preventive measures. The number of sexual partners and alcohol consumption were the most significant risk factors for HPV infection, followed by young age and lower income. Since, the vaccine against the most prevalent and high risk HPV subtypes is in use in policies regarding prevention of HPV infection might help to reduce the risk of infection and cervical cancer. However, larger epidemiological studies in different regions of our country are needed in order to report the accurate prevalence of HPV infection.

Additional file 1: Table S1. The demographic characteristics of the study population [the variables are expressed as n (\%)].

Click here for file

[http://www.biomedcentral.com/content/supplementary/1471-2334-1027-S1.DOC ]

Additional file 2: Table S2. Univariate and multivariate logistic analysis: the association between various parameters with HPV infection in the study population.

Click here for file

[http://www.biomedcentral.com/content/supplementary/1471-2334-1027-S2.DOC]

\section{Author details \\ 'Surgical Department, Naval Hospital of Athens, 70 Dinokratous, 11521 Athens, Greece. ${ }^{2} 3$ rdDepartment of Internal Medicine and Center of Diabetes, General Hospital of Nikaia "Ag. Panteleimon", 3 D.Mantouvalou, 184 54 Nikaia, Greece. ${ }^{3}$ Department of Internal Medicine, "Elena Venizelou" Hospital, Faculty of Nursing, University of Athens, 2 E.Venizelou, 11521 Athens, Greece.}

\section{Authors' contributions}

All authors participated in the collection, analysis, interpretation of data and writing of the paper. All authors read and approved the final manuscript.

\section{Competing interests}

The authors declare that they have no competing interests.

Received: 26 January 2009

Accepted: 15 February 2010 Published: 15 February 2010
References

1. Pisani P, Bari F, Parkin DM: Estimates of the world-wide prevalence of cancer for 25 sites in the adult population. Int J Cancer 2002, 97:72-81.

2. Bosch FX, Manos MM, Muñoz N, Sherman M, Jansen AM, Peto J, Schiffman MH, Moreno V, Kurman R, Shah KV: Prevalence of human Papillomavirus in cervical cancer: a worldwide perspective. J Natl Cancer Inst 1995, 87:796-802.

3. Walboomers JM, Jacobs MV, Manos MM, Bosch FX, Kummer JA, Shah KV, Snijders PJ, Peto J, Meijer CJ, Muñoz N: Human papillomavirus is a necessary cause of invasive cervical cancer worldwide. J Pathol 1999, 189:12-9.

4. Burd EM: Human papillomavirus and cervical cancer. Clinical Microbiology Reviews 2003, 16:1-17.

5. Franco EL, Schlecht NF, Saslow D: The epidemiology of cervical cancer. Cancer J 2003, 9:348-59.

6. Nobbenhuis MA, Walboomers JM, Helmerhorst TJ, Rozendaal L, Remmink AJ, Risse EK, Linden van der HC, Voorhorst FJ, Kenemans P, Meijer CJ: Relation of human papillomavirus status to cervical lesions and consequences for cervical-cancer screening: a prospective study. Lancet 1999, 354:20-25.

7. Rozendaal L, Walboomers JMM, Linden Van Der JC, Voorhorst FJ, Kenemans P, Helmerhorst Th JM, Van Ballegooijen M, Meijer CJLM: PCRbased high-risk HPV test in cervical cancer screening gives objective risk assessment of women with cytomorphologically normal cervical smears. Int J Cancer 1996, 68:766-769.

8. Meijer CJLM, Helmerhorst ThJM, Rozendaal L, Linden van der JC, Voorhorst FJ, Walboomers JMM: HPV typing and testing in gynaecological pathology: has the time come?. Histopatology 1998, 33:83-86.

9. Harro CD, Pang YY, Roden RB, Hildesheim A, Wang Z, Reynolds MJ, Mast TC, Robinson R, Murphy BR, Karron RA, Dillner J, Schiller JT, Lowy DR: Safety and immunogenicity trial in adult volunteers of a human papillomavirus 16 L1 virus-like particle vaccine. J Natl Cancer Inst 2001, 93:284-292.

10. Clifford GM, Smith JS, Plummer M, Munoz N, Franceschi S: Human papillomavirus types in invasive cervical cancer worldwide: a metaanalysis. Br J Cancer 2003, 88:63-73.

11. Manos MM, Ting Y, Wright DK, Lewis AJ, Broker TR, Wolinsky SM: Use of polymerase chain reaction amplification for the detection of genital human papillomavirus. Cancer Cells 1989, 7:209-214.

12. Munoz N, Bosch FX, de Sanjose S, Herrero R, Castellsague $X$, Shah KV, Snijders PJ, Meijer CJ, International Agency for Research on Cancer Multicenter Cervical Cancer Study Group: Epidemiologic classification of human papillomavirus types associated with cervical cancer. $N$ Engl J Med 2003, 348:518-527.

13. Koshiol J, Lindsay L, Pimenta JM, Poole C, Jenkins D, Smith JS: Persistent Human Papillomavirus Infection and Cervical Neoplasia: A Systematic Review and Meta-Analysis. Am J Epidemiol 2008, 168:123-137.

14. Dunne EF, Unger ER, Sternberg M, McQuillan G, Swan DC, Patel SS, Markowitz LE: Prevalence of HPV infection among females in the United States. JAMA 2007, 297:813-819.

15. Evander M, Edlund K, Bodén E, Gustafsson A, Jonsson M, Karlsson R, Rylander $E$, Wadell G: Comparison of a one-step and a two-step polymerase chain reaction with degenerate general primers in a population-based study of human papillomavirus infection in young Swedish women. Journal of Clinical Microbiology 1992, 30:987-992.

16. Sherman ME, Lorincz AT, Scott DR, Wacholder S, Castle PE, Glass AG, Mielzynska-Lohnas I, Rush BB, Schiffman M: Baseline cytology, human papillomavirustesting, and risk for cervical neoplasia: a 10-year cohort analysis. Journal of the National Cancer Institute 2003, 95:46-52.

17. Kroupis C, Thomopoulou G, Papathomas TG, Vourlidis N, Lazaris AC: Population-based study of human papillomavirus infection and cervical neoplasia in Athens, Greece. Epidemiol Infect 2007, 135:943-950.

18. Labropoulou V, Diakomanolis E, Dailianas S, Kalpaktsoglou K, Balamotis A, Mavromara P: Type-specific prevalence of genital human papillomaviruses in benign, premalignant, and malignant biopsies in patients from Greece. Sexually Transmitted Diseases 1997, 24:469-474.

19. Agorastos T, Bontis J, Lambropoulos AF, Constantinidis TC, Nasioutzini M, Tagou C, Katsouyiannopoulos V: Epidemiology of human papillomavirus infection in Greek asymptomatic women. Eur J Cancer Prev 1995, 4:159-167. 
20. Agorastos T, Dinas K, Lloveras B, Bosch FX, Kornegay JR, Bontis JN, de Sanjose S: Cervical human papillomavirus infection in women attending gynaecological outpatient clinics in northern Greece. European Journal of Cancer Prevention 2004, 13:145-147.

21. de Sanjose S, Almirall R, Lloveras B, Font R, Diaz M, Muñoz N, Català I, Meijer CJ, Snijders PJ, Herrero R, Bosch FX: Cervical Human papillomavirus infection in the female population in Barcelona, Spain. Sex Transm Dis 2003, 30:788-793.

22. Pham TH, Nguyen TH, Herrero R, Vaccarella S, Smith JS, Nguyen Thuy $T$, Nguyen HN, Nguyen BD, Ashley R, Snijders PJ, Meijer CJ, Muñoz N, Parkin DM, Franceschi S: Human papillomavirus infection among women in South and North Vietnam. Int J Cancer 2003, 104:213-220.

23. Shin HR, Lee DH, Herrero $R$, Smith JS, Vaccarella $S$, Hong $S H$, Jung $K Y$, Kim HH, Park UD, Cha HS, Park S, Touzé A, Muñoz N, Snijders PJ, Meijer CJ, Coursaget $P$, Franceschi $S$ : Prevalence of human papillomavirus infection in women in Busan, South Korea. Int J Cancer 2003, 103:413-421.

24. Lazcano-Ponce E, Herrero R, Muñoz N, Cruz A, Shah KV, Alonso P, Hernández P, Salmerón J, Hernández M: Epidemiology of HPV infection among Mexican women with normal cervical cytology. Int J Cancer 2001, 91:412-420.

25. Matos E, Loria D, Amestoy GM, Herrera L, Prince MA, Moreno J, Krunfly C, Brule van den AJ, Meijer CJ, Muñoz N, Herrero R, Proyecto Concordia Collaborative Group: Prevalence of human papillomavirus infection among women in Concordia, Argentina: a population-based study. Sex Transm Dis 2003, 30:593-599.

26. Clifford GM, Rana RK, Franceschi S, Smith J, Gough G, Pimenta JM: Human papillomavirus genotype distribution in low-grade cervical lesions: comparison by geographic region and with cervical cancer. Cancer Epidemiol Biomarkers Prev 2005, 14:1157-1164.

27. Dokianakis DN, Papaefthimiou M, Tsiveleka A, Spandidos D: High prevalence of HPV 18 in correlation with ras gene mutations and clinicopathological parameters in cervical cancer studied from cervical cytological smears. Oncol Rep 1999, 66:1327-1331.

28. Vassilandonopoulou G, Panotopoulou E, Fotiou S, Tserkezoglou A, Machera E, Kottaridis S: Humanpapillomaviruses in cervical cancer I. HPV16 and 18 predominate in the Greek population. Anticancer Res 1997, 17:117-120.

29. Eluf-Neto J, Booth M, Muñoz N, Bosch FX, Meijer CJLM, Walboomers JMM: Human papillomavirus and invasive cervical cancer in Brazil. $\mathrm{Br} J$ Cancer 1994, 69:114-119.

30. Chaouki N, Bosch FX, Muñoz N, Meijer CJLM, Gueddari B, El Ghazi, Deacon J, Castellsague X, Walboomers JMM: The viral origin of cervical cancer in Rabat, Morocco. Int J Cancer 1998, 75:546-554.

31. Chichareon S, Herrero R, Muñoz N, Bosch FX, Jacobs MV, Deacon J, Santamaria M, Chongsuvivatwong V, Meijer CJLM, Walboomers JMM: Risk factors for cervical cancer in Thailand: a case - control study. J Natl Cancer Inst 1998, 90:50-57.

32. Ngelangel C, Muñoz N, Bosch FX, Limson GM, Festin MR, Deacon J, Jacobs MV, Santamaria M, Meijer CJLM, Walboomers JMM: Causes of cervical cancer in the Philippines: a case - control study. J Natl Cancer Inst 1998, 90:43-49.

33. Rolon PA, Smith JS, Muñoz N, Klug SJ, Herrero R, Bosch X, Llamosas F, Meijer CJLM, Walboomers JMM: Human papillomavirus infection and invasive cervical cancer in Paraguay. Int J Cancer 2000, 85:486-491.

34. Jacobs MV, Walboomers JMM, Snijders PJF, Voorhorst FJ, Daalmeijer NF, Meijer CJLM: Age-related distribution patterns of 37 mucosotropic HPV types in women with cytologically normal cervical smears: decreased high risk/low risk ratio at older age. Int J Cancer 2000, 87:221-227.

35. Herrero R, Hildesheim A, Bratti C, Sherman M, Hutchinson M, Morales J, Balmaceda I, Greenberg MD, Alfaro M, Burk RD, Wacholder S, Schiffman MH: A population-based study of all grades of cervical neoplasia in rural Costa Rica. J Natl Cancer Inst 2000, 92:464-473.

36. Bauer HM, Hildesheim A, Schiffman MH, Glass AG, Rush BB, Scott DR, Cadell DM, Kurman RJ, Manos MM: Determinants of genital human papillomavirus infection in low-risk women in Portland, Oregon. Sex Transm Dis 1993, 20:274-278.

37. Kjaer SK, Brule van den AJ, Bock JE, Poll PA, Engholm G, Sherman ME, Walboomers JM, Meijer CJ: Determinants of genital human papillomavirus (HPV) infection in 1000 randomly chosen young Danish women with normal PAP smear: are there different risk profiles for oncogenic and non oncogenic HPV types?. Cancer Epidemiol Biomarkers Prev 1997, 6:799-805.

38. Burk RD, Kelly P, Feldman J, Bromberg J, Vermund SH, DeHovitz JA, Landesman SH: Declining prevalence of cervicovaginal human papillomavirus infection with age is independent of other risk factors. Sex Transm Dis 1996, 23:333-341.

39. Sikström B, Hellberg D, Nilsson S, Mårdh PA: Smoking, alcohol, sexual behaviour and drug use in women with cervical human papillomavirus infection. Arch Gynecol Obstet 1995, 256:131-137.

40. Tolstrup J, Munk C, Thomsen BL, Svare E, Brule van den AJ, Grønbaek M, Meijer C, Kjaer Krüger S: The role of smoking and alcohol intake in the development of high-grade squamous intraepithelial lesions among high-risk HPV-positive women. Acta Obstet Gynecol Scand 2006, 85:1114-1119.

41. Syrjänen S, Shabalova I, Petrovichev N, Kozachenko V, Zakharova T, Pajanidi J, Podistov J, Chemeris G, Sozaeva L, Lipova E, Tsidaeva I, Ivanchenko O, Pshepurko A, Zakharenko S, Nerovjna R, Kljukina L, Erokhina O, Branovskaja M, Nikitina M, Grunberga V, Grunberg A, Juschenko A, Tosi P, Cintorino M, Santopietro R, Syrjänen K: Acquisition of high-risk human papillomavirus infections and pap smear abnormalities among women in the new independent states of the Former Soviet Union. Journal of Clinical Microbiology 2004, 42:505-511.

42. Kahn JA, Lan D, Kahn RS: Sociodemographic factors associated with highrisk human papillomavirus infection. Obstet Gynecol 2007, 110:87-95.

43. Shields TS, Brinton LA, Burk RD, Wang SS, Weinstein SJ, Ziegler RG, Studentsov YY, McAdams M, Schiffman M: A case-control study of risk factors for invasive cervical cancer among U.S. women exposed to oncogenic types of human papillomavirus. Cancer Epidemiol Biomarkers Prev 2004, 13:1574-1582.

44. Peevor R, Bowden S, Jones J, Fiander AN, Hibbitts S: Human Papillomavirus negative but dyskaryotic cervical cytology: re-analysis of molecular testing. J Clin Virol 2009, 44:322-324.

45. Kulasingam SL, Hughes JP, Kiviat NB, Mao C, Weiss NS, Kuypers JM, Koutsky LA: Evaluation of human papillomavirus testing in primary screening for cervical abnormalities: comparison of sensitivity, specificity, and frequency of referral. JAMA 2002, 288:1749-1757.

\section{Pre-publication history}

The pre-publication history for this paper can be accessed here:http://www biomedcentral.com/1471-2334/10/27/prepub

doi:10.1186/1471-2334-10-27

Cite this article as: Stamataki et al:: Prevalence of HPV infection among Greek women attending a gynecological outpatient clinic. BMC Infectious Diseases 2010 10:27.

\section{Submit your next manuscript to BioMed Central and take full advantage of:}

- Convenient online submission

- Thorough peer review

- No space constraints or color figure charges

- Immediate publication on acceptance

- Inclusion in PubMed, CAS, Scopus and Google Scholar

- Research which is freely available for redistribution

Submit your manuscript at www.biomedcentral.com/submit
C Biomed Central 